\title{
Diagnosis of coronary artery disease by estimation of coronary sinus lactate
}

\author{
GRAHAM JACKSON, LYNNE ATKINSON, MICHAEL CLARK ${ }^{1}$, \\ BERESFORD CROOK, PETER ARMSTRONG, AND SAMUEL ORAM
}

From the Cardiac and Radiology Departments, King's College Hospital, London

SUMMARY In an attempt to assess the value of coronary sinus lactate estimation before and during atrial pacing for the diagnosis of obstructive coronary artery disease, 70 patients with angina were investigated in this way and by selective coronary arteriography. Thirty-five had radiologically normal coronary arteries and 35 had coronary artery disease. When the change in coronary arteriovenous lactate difference was less than $0.09 \mathrm{mmol} / 1(0.8 \mathrm{mg} / 100 \mathrm{ml})$ between the control and the peak atrial pacing sample, the coronary arteries were normal except in one patient who had distal disease of a single vessel. When the change was greater than $0.22 \mathrm{mmol} / 1(2.0 \mathrm{mg} / 100 \mathrm{ml})$ coronary artery disease was always found, and when the change was greater than $0.39 \mathrm{mmol} / 1(3.5 \mathrm{mg} / 100 \mathrm{ml})$ there was always disease of two or three vessels. Unfortunately, the presence or absence of coronary artery disease could not be predicted when the change fell between 0.09 and $0.22 \mathrm{mmol} / 1(0.8$ and $2.0 \mathrm{mg} / 100 \mathrm{ml})$. Estimation of coronary sinus lactate before and during atrial pacing can thus frequently distinguish patients with normal coronary arteries from those with coronary artery disease.

The diagnosis of angina pectoris is based upon interpretation of the patient's history. Though most patients with angina pectoris have obstructive coronary artery disease, between 5 and 10 per cent have normal coronary arteries (Kemp et al., 1973). So far, no investigation other than selective coronary arteriography has been able to differentiate these two groups.

In this study we compared the change in level of coronary sinus lactate after atrial pacing with the findings at coronary arteriography. Additional diagnostic information obtained included resting and radiotelemetric exercise-electrocardiograms and fasting lipid estimations.

\section{Patients and methods}

\section{PATIENTS}

Seventy patients, 46 men and 24 women, aged 26 to 70 years (mean 49 years) were investigated. The clinical diagnosis of angina pectoris was graded as 'definite' or 'uncertain' before beginning investigations. No patient suffered from anaemia, thyroid disease, diabetes, valvar heart disease, or autoimmune disease. Before the investigation beta-

'Pfizer Limited, Sandwich, Kent.

Received for publication 5 September 1977 blocking drugs were discontinued for 1 week and digoxin for 2 weeks.

\section{ELECTROCARDIOGRAPHY}

A resting 12-lead electrocardiogram was recorded immediately before the exercise test which was carried out as previously described (Jackson et al., 1975). Using radiotelemetry, ST segment depression in lead V5 was measured before and after exercise. Myocardial ischaemia was considered to be present when there was ST segment depression of at least $1 \mathrm{~mm}$ for $0.08 \mathrm{~s}$ or more in at least 5 consecutive beats.

CORONARY SINUS LACTATE PACING STUDY Myocardial metabolism is normally aerobic, but in the presence of ischaemia anaerobic metabolism develops, resulting in a decrease in lactate extraction by the myocardium. In our studies the coronary arterial lactate was assumed to be the same as that of the femoral artery. The investigation was performed on a separate occasion to coronary arteriography. After the patient had rested for 45 minutes, a Zucker bipolar electrode catheter (Zucker et al., 1965) was inserted into an antecubital vein, and the tip was fluoroscopically positioned $2 \mathrm{~cm}$ within the main coronary sinus as viewed in the anteroposterior projection. The position of the tip was 
repeatedly checked by injection of contrast medium. Arterial samples were obtained from the femoral artery through a No. $19 \mathrm{G}$ needle inserted under local anaesthesia, and femoral arterial pressure was recorded throughout the study on a Mingograph 81 recorder. Both the venous catheter and arterial needle were intermittently flushed with heparinised saline. Before pacing at least two control samples were taken simultaneously from the coronary sinus and femoral artery. Using a battery-powered pacemaker (Devices) the heart rate was increased at 5 -second intervals by increments of 10 beats per minute. The peak pacing rate was at least 10 beats above the peak exercise rate or the maximum predicted heart rate (Lange Andersen et al., 1971), whichever was the greater, and was discontinued as soon as the patient experienced his usual chest discomfort or pain of a severity that would stop him in his normal daily life. Blood samples were taken at peak pacing and at 2,5 , and 10 minutes after cessation of pacing. Electrocardiograms were taken throughout the study. Lactate was estimated by Livesley's (Livesley and Atkinson, 1974) modification of Hohorst's method. Myocardial extraction ratio is defined as the difference between arterial and coronary sinus lactate, divided by arterial lactate, and expressed as a percentage. At peak pacing, myocardial ischaemia is indicated by either a lactate extraction ratio of less than 10 per cent or a coronary sinus lactate greater than the arterial lactate (Cohen et al., 1966). A change in coronary arteriovenous lactate difference of greater than $0.09 \mathrm{mmol} / 1(0.8 \mathrm{mg} / 100 \mathrm{ml})$ between control samples and samples at peak pacing has previously been considered to indicate the presence of coronary artery disease (Livesley and Oram, 1973) and we have compared this measurement with the lactate extraction ratio.

\section{ANGIOCARDIOGRAPHY}

Selective coronary arteriography was performed by either the Sones or the Judkins technique using 76 per cent or 85 per cent meglumine/sodium diatrizoate mixtures, and recorded in a single plane on $35 \mathrm{~mm}$ film at 50 frames a second using a Siemens $\mathrm{H}$ type intensifier system. Left ventriculography was performed in the right anterior oblique $\overrightarrow{0}$ position. The angiograms were interpreted on two separate occasions without knowledge of the results of the other investigations. Patients with coronary artery disease were grouped according to the presence of at least 50 per cent narrowing in 1,2, or 3 major vessels. The left ventricle was considered abnormal if the ejection fraction was less than 50 per cent or localised akinesia or dyskinesia was present.

\section{LIPIDS}

Fasting plasma lipids were estimated on 3 separate occasions and were considered pathological when the cholesterol was greater than $6.50 \mathrm{mmol} / \mathrm{l}$ $(250 \mathrm{mg} / 100 \mathrm{ml})$ and $/$ or triglycerides greater than $1.70 \mathrm{mmol} / 1(150 \mathrm{mg} / 100 \mathrm{ml})$, with or without electrophoretic abnormalities.

\section{BLOOD PRESSURE}

Five of the 70 patients had hypertension as defined by a diastolic pressure greater than $100 \mathrm{mmHg}$ on 3 separate occasions after the patient had been resting supine for 5 minutes. In all, this was essential hypertension.

\section{COMPLICATIONS}

There were none throughout the study.

\section{Results}

A summary of clinical and electrocardiographic findings is shown in Table 1 and the results of

Table 1 Clinical and electrocardiographic data

\begin{tabular}{|c|c|c|c|c|c|}
\hline & \multicolumn{2}{|c|}{ Normal coronary arteries } & \multicolumn{3}{|c|}{ Coronary artery disease } \\
\hline & \multicolumn{2}{|c|}{$\begin{array}{l}\text { Change in arteriovenous lactate difference } \\
\text { on pacing }\end{array}$} & \multicolumn{3}{|c|}{ No. of diseased arteries } \\
\hline & $<0.8 \mathrm{mg} / 100 \mathrm{ml}$ & $>0.8 \mathrm{mg} / 100 \mathrm{ml}$ & 1 & 2 & 3 \\
\hline $\begin{array}{l}\text { No. of patients } \\
\text { Clinical diagnosis of angina }\end{array}$ & 16 & 19 & 6 & 13 & 16 \\
\hline $\begin{array}{l}\text { 'Definite' } \\
\text { 'Uncertain' }\end{array}$ & $\begin{array}{r}3 \\
13\end{array}$ & $\begin{array}{r}17 \\
2\end{array}$ & $\begin{array}{l}6 \\
0\end{array}$ & $\begin{array}{r}12 \\
1\end{array}$ & $\begin{array}{r}16 \\
0\end{array}$ \\
\hline $\begin{array}{l}\text { Abnormal resting electrocardiogram } \\
\text { Abnormal exercise electrocardiogram } \\
\text { Mean exercise ST depression (mm) } \\
\text { Abnormal resting and/or exercise electrocardiogram } \\
\text { Abnormal pacing electrocardiogram } \\
\text { Mean peak pacing ST depression (mm) }\end{array}$ & $\begin{array}{l}2(13 \%) \\
2(13 \%) \\
0 \cdot 13 \pm 0 \cdot 1 \\
3(19 \%) \\
4(25 \%) \\
0 \cdot 5 \pm 0 \cdot 2\end{array}$ & $\begin{array}{c}5(26 \%) \\
8(42 \%) \\
0.7 \pm 0.2 \\
12(63 \%) \\
13(68 \%) \\
0.7 \pm 0.2\end{array}$ & $\begin{array}{l}1(16 \%) \\
2(33 \%) \\
0.6 \pm 0.4 \\
2(33 \%) \\
2(33 \%) \\
0.75 \pm 0.5\end{array}$ & $\begin{array}{c}5(38 \%) \\
8(61 \%) \\
0.85 \pm 0.3 \\
11(85 \%) \\
9(69 \%) \\
1.15 \pm 0.25\end{array}$ & $\begin{array}{l}15(94 \%) \\
11(69 \%) \\
1.53 \pm 0.4 \\
15(94 \%) \\
12(75 \%) \\
1.75 \pm 0.3\end{array}$ \\
\hline
\end{tabular}

For conversion from traditional units to $S I$ units: Lactate $1 \mathrm{mg} / 100 \mathrm{ml} \sim 0.111 \mathrm{mmol} / 1$. 
Table 2 Lactate measurements in patients with healthy and diseased coronary arteries

\begin{tabular}{|c|c|c|c|c|c|}
\hline & \multicolumn{2}{|c|}{ Normal coronary arteries } & \multicolumn{3}{|c|}{ Coronary artery disease } \\
\hline & \multicolumn{2}{|c|}{$\begin{array}{l}\text { Change in arteriovenous lactate } \\
\text { difference on pacing }\end{array}$} & \multicolumn{3}{|c|}{ No. of diseased arteries } \\
\hline & $<0.8 \mathrm{mg} / 100 \mathrm{ml}$ & $>0.8 \mathrm{mg} / 100 \mathrm{ml}$ & 1 & 2 & 3 \\
\hline \multirow{7}{*}{$\begin{array}{l}\text { No. of patients } \\
\text { Mean control minus peak pacing lactate } \\
\text { arteriovenous difference }(\mathrm{mg} / 100 \mathrm{ml}) \\
\text { Mean lactate extraction ratio } \% \text { on } \\
\text { peak pacing } \\
\text { Abnormal lactate metabolism } 2 \text { minutes } \\
\text { after stopping pacing } \\
\text { Mean arterial lactate (mg/100 ml) } \\
\text { Lactate production (i.e. coronary sinus lactate } \\
\text { more than femoral arterial) }\end{array}$} & 16 & 19 & 6 & 13 & 16 \\
\hline & $0 \cdot 15 \pm 0.1$ & $1.16 \pm 0.04$ & $0.93+0.3$ & $2 \cdot 3+0 \cdot 3$ & $3.3 \pm 0.7$ \\
\hline & & & & & \\
\hline & $27 \cdot 6 \pm 2 \cdot 9$ & $10 \cdot 7 \pm 2 \cdot 81$ & $26 \cdot 9 \pm 4 \cdot 3$ & $-0.1 \pm 5.9$ & $-18.6 \pm 13.5$ \\
\hline & 0 & $9(47 \%)$ & $4(66 \%)$ & $10(77 \%)$ & $16(100 \%)$ \\
\hline & $6.2 \pm 0.4$ & $7 \cdot 0 \pm 0.5$ & $6.98 \pm 0.9$ & $7 \cdot 69 \pm 0.6$ & $7 \cdot 6 \pm 0 \cdot 7$ \\
\hline & 0 & 0 & 0 & $6(46 \%)$ & $10(62 \%)$ \\
\hline
\end{tabular}

For conversion from traditional units to SI units: Lactate: $1 \mathrm{mg} / 100 \mathrm{ml} \bumpeq 0.111 \mathrm{mmol} / 1$.

lactate measurements are given in Table 2. Patients were divided into two main groups, those with normal coronary arteries and those with one or more stenoses of more than 50 per cent in at least one major coronary artery. Patients with normal coronary arteries were subdivided into 2 groups based on a change in arteriovenous lactate difference greater or less than $0.09 \mathrm{mmol} / 1(0.8 \mathrm{mg} / 100 \mathrm{ml})$ between control and peak pacing samples. Patients with coronary artery disease were subdivided into those with disease of 1,2 , or 3 vessels. Nonparametric statistical tests were used to evaluate the significance of the correlations between the variables. These included the $\chi^{2}$ goodness of fit test for contingency tables, the Mann-Whitney U-test, Spearman's coefficient of rank correlation, and the Kruskal-Wallis one-way analysis of variance.

CORONARY AND LEFT VENTRICULOGRAPHY Thirty-five patients had normal coronary arteries and 35 had coronary artery disease. Of the latter group, 16 had significant disease of 3 arteries, 13 of 2 arteries, and 6 of a single artery. Abnormal left ventricular function was found in 5 patients, all with coronary artery disease, 4 of whom had disease of all 3 vessels. Fifty-seven per cent of patients with normal coronary arteries and 97 per cent with coronary artery disease had typical angina pectoris.

\section{ELECTROCARDIOGRAPHY}

Resting electrocardiograms showed ischaemia in 7 patients with normal coronary arteries (20\%) and in 21 patients with coronary artery disease (60\%). After exercise a further 8 patients with normal coronary arteries developed abnormal electrocardiograms, making a total of $15(43 \%)$. In those with coronary artery disease, the number of patients with abnormal electrocardiograms rose after exercise testing from 21 to $28(80 \%)$.

The more extensive the coronary artery disease the more likely a patient was to have an abnormal resting electrocardiogram $(P<0.01)$. Furthermore, the more extensive the coronary artery disease the greater was the degree of ST segment depression induced by exercise $(P<0.05)$. However, it is clear that electrocardiography alone fails to differentiate between patients with normal coronary arteries and those with coronary artery disease, as not only is the electrocardiogram frequently normal in the presence of coronary artery disease, but also it may be abnormal in the absence of coronary artery disease. Neither the presence nor the degree of ST segment depression after atrial pacing differentiated between the two groups.

\section{CORONARY SINUS LACTATE}

We found that a change in coronary arteriovenous lactate difference between the control and the peak pacing samples of more than $0.09 \mathrm{mmol} / 1(0.8$ $\mathrm{mg} / 100 \mathrm{ml}$ ) correlated with a lactate extraction ratio of less than 10 per cent $(P<0.001)$ in patients with normal coronary arteries and in those with coronary artery disease. There is very little to choose between these methods of expressing lactate abnormalities. An arteriovenous lactate difference of less than $0.09 \mathrm{mmol} / 1(0.8 \mathrm{mg} / 100 \mathrm{ml})$ was associated with normal coronary arteries in all but one patient who had a single distal lesion of the circumflex artery (Table 3 ).

No patient with normal coronary arteries had an arteriovenous lactate difference of more than $0.22 \mathrm{mmol} / 1(2.0 \mathrm{mg} / 100 \mathrm{ml})$. In the range 0.09 to $0.22 \mathrm{mmol} / 1(0.8 \mathrm{mg}$ to $2.0 \mathrm{mg} / 100 \mathrm{ml})$ there were patients both with and without coronary artery disease. A change in arteriovenous difference greater than $0.39 \mathrm{mmol} / 1(3.5 \mathrm{mg} / 100 \mathrm{ml})$ was 
Table 3 Correlation between abnormal lactate metabolism on atrial pacing and extent of coronary artery disease

\begin{tabular}{lllll}
\hline $\begin{array}{l}\text { Control minus peak pacing } \\
\text { arteriovenous lactate } \\
\text { difference }(\mathrm{mg} / 100 \mathrm{ml})\end{array}$ & \multicolumn{4}{l}{ No. of diseased arteries } \\
\cline { 2 - 5 } & $\begin{array}{l}0 \\
(n=35)\end{array}$ & $\begin{array}{l}1 \\
(n=6)\end{array}$ & $\begin{array}{l}2 \\
(n=13)\end{array}$ & $\begin{array}{l}3 \\
(n=16)\end{array}$ \\
\hline $\begin{array}{l}0-0.8 \mathrm{mg} \\
(0-0.09 \mathrm{mmol} / \mathrm{l})\end{array}$ & 16 & 1 & 0 & 0 \\
$\begin{array}{l}0.8-2 \cdot 0 \\
(0.09-0.22 \mathrm{mmol} / \mathrm{l})\end{array}$ & 19 & 4 & 7 & 8 \\
$\begin{array}{l}2.0-3.5 \\
(0.22-0.39 \mathrm{mmol} / \mathrm{l})\end{array}$ & 0 & 1 & 4 & 1 \\
$\begin{array}{l}3.5 \\
(>0.39 \mathrm{mmol} / \mathrm{l})\end{array}$ & 0 & 0 & 2 & 7 \\
\hline
\end{tabular}

$\mathbf{n}=$ no. of patients.

For conversion from traditional units to SI units: Lactate: $1 \mathrm{mg} / 100 \mathrm{ml}$ $\bumpeq 0.111 \mathrm{mmol} / 1$.

diagnostic of disease of 2 or 3 vessels. Thus the extent of the coronary artery disease paralleled the degree of change in arteriovenous lactate difference on pacing $(P<0.001)$. The presence of abnormal lactate metabolism for 2 minutes after cessation of atrial pacing did not differentiate between patients with normal coronary arteries and those with coronary artery disease. Only in the presence of coronary artery disease did lactate production on atrial pacing result in coronary sinus levels greater than arterial.

\section{PLASMA LIPID PROFILES}

These were abnormal in 14 per cent of patients with normal coronary arteries and in 66 per cent of those with coronary artery disease. Abnormal fasting lipids correlated significantly with the extent of coronary artery disease $(P<0.05)$ but were not significantly related to changes in the electrocardiogram, coronary sinus lactate changes, or any other variable.

Since the lipid abnormalities did not seem to be related to the change in arteriovenous lactate difference on pacing, and since both were independently significantly correlated with the severity of coronary artery disease, it seemed likely that when both were abnormal this would more reliably predict coronary artery disease. In fact, we found that patients with both raised plasma lipids and abnormal coronary sinus lactate on atrial pacing were more likely to have coronary artery disease than when only one of these was abnormal $(P<$ $0.005)$.

\section{Discussion}

Typical angina pectoris can occur in patients shown to have normal major coronary vessels on selective coronary arteriography (Kemp et al., 1973). Fifty- seven per cent of our patients with normal coronary arteries and 97 per cent of those with coronary artery disease had clinically typical angina. The presence of anginal pain does not, therefore, necessarily imply the presence of coronary artery disease.

Measurement of coronary sinus lactate before and after atrial pacing stress can determine the presence or absence of anaerobic metabolism under these conditions and, subject to certain anatomical limitations, is the most reliable means of assessing this (Gorlin, 1969). We have assessed the value of coronary sinus lactate estimation in predicting the presence or absence of coronary artery disease. Though the procedure is invasive it can be performed on an outpatient basis and in our hands has not been associated with any morbidity or mortality. Though a previous study suggested that the presence of abnormal lactate metabolism after atrial pacing was diagnostic of coronary artery disease, coronary arteriographic proof was not obtained (Livesley and Oram, 1973). Furthermore, abnormal myocardial lactate metabolism on atrial pacing has also been shown in the presence of normal coronary arteries (Boudoulas et al., 1974; Richardson et al., 1974). In this study, we therefore correlated the coronary angiographic findings with the abnormalities of lactate metabolism. All patients with a change in arteriovenous lactate difference of less than 0.09 $\mathrm{mmol} / 1(0.8 \mathrm{mg} / 100 \mathrm{ml})$ on pacing had normal coronary arteries with the exception of one who had localised distal disease of one artery. This illustrates the limitation of sampling the main coronary sinus in the presence of localised regional ischaemia (Herman et al., 1967); the normal result in the presence of distal disease probably reflects dilution of the lactate from the ischaemic myocardium by the venous blood from the larger aerobic zones. All patients with a control minus peak pacing arteriovenous lactate difference of greater than $0.22 \mathrm{mmol} / \mathrm{l}$ $(2.0 \mathrm{mg} / 100 \mathrm{ml})$ had coronary artery disease but a difference between 0.09 and $0.22 \mathrm{mmol} / 1(0.8$ and $2.0 \mathrm{mg} / 100 \mathrm{ml}$ ) did not distinguish between those with normal coronary arteries and those with coronary artery disease.

The conclusion is that the estimation of coronary sinus lactate before and after atrial pacing is a reliable method of demonstrating the presence of extensive coronary artery disease when the control minus peak pacing arteriovenous lactate difference is greater than $0.22 \mathrm{mmol} / 1(2 \mathrm{mg} / 100 \mathrm{ml})$; additionally, the absence of clinically important coronary artery disease can be assumed when the change is less than $0.09 \mathrm{mmol} / 1(0.8 \mathrm{mg} / 100 \mathrm{ml})$. However, if the change is between 0.09 and $0.22 \mathrm{mmol} / 1$ $(0.8$ and $2.0 \mathrm{mg} / 100 \mathrm{ml})$ this finding alone is not 
diagnostic of coronary artery disease, but when the lipids are abnormal the presence of coronary artery disease is more likely. The association of increased lipid levels with abnormal lactate metabolism may provide a useful screening test for the detection of coronary artery disease.

This project was supported by a Pfizer Research Grant.

\section{References}

Boudoulas, H., Cobb, T. C., Leighton, R. F., and Wilt, S. M. (1974). Myocardial lactate production in patients with angina-like chest pain and angiographically normal coronary arteries and left ventricle. American fournal of Cardiology, 34, 501-505.

Cohen, L. S., Elliott, W. C., Klein, M. D., and Gorlin, R. (1966). Coronary heart disease: clinical, cinearteriographic and full metabolic correlations. American fournal of Cardiology, 17, 153-168.

Gorlin, R. (1969). Evaluation of myocardial metabolism in ischaemic heart disease. Circulation, 39, Suppl. IV, 155-163.

Herman, M. V., Elliott, W. C., and Gorlin, R. (1967). An electrocardiographic anatomic and metabolic study of zonal myocardial ischemia in coronary heart disease.
Circulation, 35, 834-846.

Jackson, G., Atkinson, L., and Oram, S. (1975). Double-blind evaluation of tolamolol, propranolol, practolol and placebo in the treatment of angina pectoris. British Medical fournal, 1, 708-712.

Kemp, H. G., Jr., Vokonas, P. S., Cohn, P. F., and Gorlin, R. (1973). The anginal syndrome associated with normal coronary arteriograms. American fournal of Medicine, 54, 735-742.

Lange Andersen, K., Shephard, R. J., Denolin, H., Varnauskas, E., and Masironi, E. (1971). Fundamentals of Exercise Testing. World Health Organization, Geneva.

Livesley, B., and Atkinson, L. (1974). Accurate quantitative estimation of lactate in whole blood. Clinical Chemistry, 20, 1478.

Livesley, B., and Oram, S. (1973). Diagnosis of doubtful angina. Lancet, 1, 1461-1465.

Richardson, P. J., Livesley, B., Oram, S., Olsen, E. G. J., and Armstrong, P. (1974). Angina pectoris with normal coronary arteries; transvenous myocardial biopsy in diagnosis. Lancet, 2, 677-680.

Zucker, I. R., Rothfeld, E. L., and Bernstein, A. (1965). A new multi-purpose cardiac catheter. American fournal of Cardiology, 15, 45-47.

Requests for reprints to Dr Samuel Oram, Cardiac Department, King's College Hospital, Denmark Hill, London SE5 9RS. 